\title{
Bridging the Gap Between Adolescence and Adulthood: the Challenges of Emerging Adults
}

\section{Linda Rosenberg, MSW}

Katelin Ferrell is 17 and has struggled with depression and behavioral health problems since grade school. ${ }^{1}$ She and her mother thought county officials would help them find a "safe place," a mental health facility where she could get professional therapy. Instead, Katelin wound up in a county correctional facility, where staff often behave more like prison guards than therapists.

For the 11 months since he turned 18, Matthew Hoff has drifted through a circuit of hospitals, homeless shelters, and jails. ${ }^{2}$ Matthew was diagnosed with bipolar disorder, post-traumatic stress disorder, and other mental illnesses. He also uses methamphetamine. Fearing for his life, his mother begged police to evaluate her son for an involuntary, 72-hour, psychiatric hold, but was told that Matthew is not "gravely disabled."

The transition from adolescence to adulthood is a vulnerable period when young people take their first definitive steps toward independence and begin to enter their new role as adults. It is also a period when serious mental disorders can begin to manifest, and the temptation to use drugs and alcohol is enhanced by newfound freedom and peer pressure. By the time they are high school seniors, almost $70 \%$ of students have tried alcohol, half have taken an illegal drug, and more than $20 \%$ have used a prescription drug for non-medical purposes. ${ }^{3}$

Data clearly show that we need to focus on helping young people:

- About one in five, 6.4 million young adults, ages 18 to 25 years, experienced a mental illness in the past year; ${ }^{4}$

- only $11.4 \%$ of them received mental health services in the past year; ${ }^{4}$

- seventy-five percent of mental and substance use disorders emerge before the age of $25 ;^{5}$

- the rate of substance use disorder among people ages 18 to 25 is twice that of adults 26 and older; ${ }^{6}$ and

- more than $32 \%$ of 18 - to 25 -year-olds with a severe mental illness and $40 \%$ of those with any mental illness also have a substance use disorder. ${ }^{6}$

In April 2015, the Journal of Behavioral Health Services \& Research (JBHS\&R) addressed this critical problem with a special issue devoted to "Interventions for Emerging Adults with Serious Mental Health Conditions." Then, I promised you that the National Council was committed to advocating for policy changes that will ensure patients' access at all points along the spectrum of mental illness. Now, I am pleased to share some progress and initiatives.

Address correspondence to Linda Rosenberg, MSW, National Council for Behavioral Health, Washington, DC, USA. Email: LindaR@TheNationalCouncil.org.

Journal of Behavioral Health Services \& Research, 2016. 518-520. (c) 2016 National Council for Behavioral Health. DOI 10.1007/s11414-016-9535-6 
We are building the foundation for preventive care to ensure treatment is available to young people like Katelin before they experience a crisis. The Substance Abuse and Mental Health Services Administration (SAMHSA) has required states to set aside five percent of the Mental Health Block Grant to support evidence-based programs focused on early intervention for serious mental illness. As I write this, the House and Senate have not yet finalized the budget for fiscal year 2017. However, the House and Senate Labor, Health, and Human Services and Education Appropriation Subcommittees have approved spending bills that include a 10\% set-aside for the second year in a row. ${ }^{7}$ Fostering Futures, an innovative partnership with the State of Wisconsin, will help make trauma-informed care the norm, not the exception. Championed by Wisconsin's First Lady Tonette Walker, this initiative infuses trauma-informed approaches into county- and state-level departments to create a more trauma-aware culture. ${ }^{8}$ Starting in October 2016, behavioral health providers will be able to earn a certificate in children's services through a series of online courses with Relias Learning. ${ }^{9}$

State-based peer counseling programs show tremendous promise spanning the gap between child and adult service systems to reach youth like Matthew when the system fails them. Genesis Club in Massachusetts and Thresholds Youth Program in Chicago are providing support services for young adults aged 18-25 for employment, education, housing, and social connection through programs that utilize the skills of peer counselors who break down age-based barriers. ${ }^{10}$

Youth Mental Health First Aid is educating adults to recognize when adolescents and transitionaged youth are experiencing mental illness and addictions or are in crisis. The course is tailored to introduce common mental health challenges for youth, reviews typical adolescent development, and teaches a five-step action plan to help young people in crisis and non-crisis situations. In 2017, the National Council will offer a new peer-to-peer program in the USA named Teen Mental Health First Aid.

A $\$ 2$ million grant from the Conrad N. Hilton Foundation will equip primary care providers with the tools to identify and address adolescent substance use early on. ${ }^{11}$ Primary care providers report they are unprepared to talk with adolescent patients about alcohol use. ${ }^{12}$ That is why we are developing a standardized implementation model, or change package, for health care professionals to conduct screening, brief intervention, and referral to treatment (SBIRT) for youth in a way that encourages communication and facilitates early response.

There is much hard work ahead to ensure that emerging adults receive the care and protection they need and deserve, but there is a lot of hope in the special section of this issue of $J B H S \& R$ : new systems of care; blueprints for intervention; and promising new programs.

\section{References}

1. Serres C. Confined without charges, a teenager's ordeal reveals strains within Minnesota's juvenile correctional system. Star Tribune. August 7, 2016. Available online at www.startribune.com/confined-without-charges-a-teenager-s-ordeal-reveals-strains-within-minnesotas-juvenile-correctional-system/389387061. Accessed on August 30, 2016.

2. Woo M. When a mentally ill child becomes a mentally ill adult. $O C$ Weekly. March 22, 2012. Available online at www.ocweekly.com/ news/when-a-mentally-ill-child-becomes-a-mentally-ill-adult-6421517. Accessed on August 30, 2016.

3. Johnston LD, O'Malley PM, Bachman JG, et al. Monitoring the Future National Results on Adolescent Drug Use: Overview of Key Findings. Bethesda: MD: National Institute on Drug Abuse, 2013.

4. Substance Abuse and Mental Health Services Administration. The CBHSG Report: Serious Mental Health Challenges among Older Adolescents and Young Adults. Rockville, MD: Center for Behavioral Health Statistics and Quality, 2014. Available online at www.samhsa.gov/data/sites/default/files/sr173-mh-challenges-young-adults-2014/sr173-mh-challenges-young-adults-2014/sr173-mhchallenges-young-adults-2014.htm\#fn17. Accessed on August 30, 2016.

5. McGorry, P. Transition to adulthood: The critical period for pre-emptive, disease-modifying care for schizophrenia and related disorders. Schizophrenia Bulletin. 2011; 37(3): 524-530.

6. Substance Abuse and Mental Health Services Administration. Results from the 2012 National Survey on Drug Use and Health: Summary of National Findings. NSDUH Series H-46, HHS Publication No. SMA 13-4795, Rockville, MD: Center for Behavioral Health Statistics and Quality, 2013. 
7. Substance Abuse and Mental Health Services Administration. SAMHSA'S FY 2017 Budget as Proposed in the President's Budget. Washington, DC. 2016. Available online at http://store.samhsa.gov/shin/content//SMA16-KENOMOTO021016/SMA16KENOMOTO021016.pdf. Accessed on August 30, 2016.

8. Fostering Futures. Trauma Informed Care. Available online at www.fosteringfutureswisconsin.org. Accessed on August 30, 2016.

9. Relias Learning. Certificates of Excellence. Available online at https://www.reliaslearning.com/partners/national-council. Accessed on August 30, 2016

10. National Alliance on Mental Health. Road to Recovery: Employment and Mental Illness. Arlington, VA. 2014. Available online at www.nami.org/About-NAMI/Publications-Reports/Public-Policy-Reports/RoadtoRecovery.pdf. Accessed on August 30, 2016.

11. National Council for Behavioral Health. Conrad N. Hilton Foundation Awards National Council \$2M for Screening, Brief Intervention and Referral to Treatment (SBIRT) Learning Initiative. Washington, DC. 2016. Available online at www.thenationalcouncil.org/pressreleases/conrad-n-hilton-foundation-awards-national-council-2m-screening-brief-intervention-referral-treatment-sbirt-learning-initiative/. Accessed on August 30, 2016.

12. The National Center on Addiction and Substance Abuse at Columbia University. National survey of primary care physicians and patients on substance abuse. Available online at http://www.centeronaddiction.org/addiction-research/reports/national-survey-american-attitudessubstance-abuse-teens-2012. Accessed on August 30, 2016. 